\title{
Say NO to Neurodegeneration: Role of S-Nitrosylation in Neurodegenerative Disorders
}

\author{
Kenny K.K. Chung \\ Department of Biochemistry, Hong Kong University of Science and Technology, Clear Water Bay, \\ Hong Kong, SAR China
}

\section{Key Words}

S-nitrosylation $\cdot$ Neurodegeneration $\cdot$ Nitric oxide $\cdot$

Neurodegenerative disorders

\begin{abstract}
Nitric oxide (NO) is an important signaling molecule that controls a wide range of biological processes. One of the signaling mechanisms of NO is through the S-nitrosylation of cysteine residues on proteins. S-nitrosylation is now regarded as an important redox signaling mechanism in the regulation of different cellular and physiological functions. However, deregulation of S-nitrosylation has also been linked to various human diseases such as neurodegenerative disorders. Nitrosative stress has long been considered as a major mediator in the development of neurodegeneration, but the molecular mechanism of how NO can contribute to neurodegeneration is not completely clear. Early studies suggested that nitration of proteins, which can induce protein aggregation might contribute to the neurodegenerative process. However, several recent studies suggest that S-nitrosylation of proteins that are important for neuronal survival contributes substantially in the development of various neurodegenerative disorders. Thus, in-depth understanding of the mechanism of neurodegeneration in relation to S-nitrosylation will be critical for the development of therapeutic treatment against these neurodegenerative diseases.

Copyright $\odot 2007$ S. Karger AG, Basel
\end{abstract}

\section{Introduction}

Nitric oxide (NO) is a well-known signaling molecule that induces endothelium relaxation in response to a variety of stimuli. In mammals, NO is synthesized by nitric oxide synthases (NOS) through the conversion of L-arginine to $\mathrm{NO}$ and L-citrulline. The discovery of $\mathrm{NO}$ as an endothelium-derived relaxing factor (EDRF) was more than two decades ago, and since then, increasing numbers of pathways have been shown to be modulated by NO. However, imbalance of NO signaling has also been linked to different human diseases. In particular, increasing evidence suggests that S-nitrosylation is involved in the pathogenic process of various neurodegenerative disorders. Therefore, a thorough understanding of how NO modulates different physiological and cellular pathways will identify potential new pharmacological targets for neurodegeneration in the future.

\section{How NO Mediates Signal Transduction}

Initial work showed that NO mediates its effect by activating guanylate cyclases (GC) through the binding of NO to the heme group of GC [1]. This binding induces a conformational change and activates the enzyme for the production of cGMP [1]. Increased level of cGMP then activates selected pathways to induce cellular responses

\section{KARGER \\ Fax +41613061234 \\ E-Mail karger@karger.ch}

www.karger.com

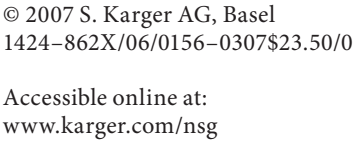

\footnotetext{
Kenny K.K. Chung

Department of Biochemistry, Hong Kong University of Science and Technology Clear Water Bay

Hong Kong, SAR (China)

Tel. +852 2358 8019, Fax +852 2358 1552, E-Mail bckchung@ust.hk
} 
such as vasodilation [1]. Aside from the heme group, NO also reacts with cysteine residues on target proteins to form nitrosothiols that mediate signal transduction. Snitrosylation is a reversible process that is facilitated by an acid-base amino acid motif within the protein structure $[2,3]$. This characteristic motif was discovered by alignment of proteins shown to be S-nitrosylated by NO [3]. An example of this motif is found on the beta subunit of hemoglobin in which the Cys93 (His92-Cys93-Asp94) is known to be modified by $\mathrm{NO}$ [3]. However, an important feature of the acid-base motif is that it is not restricted to the primary structure of the protein sequence. For example, cysteine residues 221 and 273 of dimethylargininase-1 (DDAH-1) are modified by NO through S-nitrosylation, but these cysteines (Asn220-Cys221-Ile222 and Thr272-Cys273-Cys274) are not flanked by acidic or basic amino acids on the primary sequence [4]. Instead, these cysteine residues (Cys221 and Cys273) are surrounded by acidic and basic amino acids that are brought together through structural folding [4].

Although attempts have been make to elucidate how proteins are being S-nitrosylated, the exact mechanism is not clear. It is hypothesized that the transfer of $\mathrm{NO}$ group between nitrosothiols is the major route of how S-nitrosylation signaling is being conducted. The most common reservoir of nitrosothiols is S-nitrosoglutathione (GSNO). GSNO is generated when NO reacts with oxygen to form $\mathrm{N}_{2} \mathrm{O}_{3}$ which subsequently reacts with glutathione to form the GSNO. Several enzymes have been identified to metabolize GSNO and to facilitate S-nitrosylation as the signaling mechanism for NO. For instance, gamma-glutamyl transpeptidase (GGT) converts GSNO to S-nitrosocysteinyl glycine (CGSNO), which is a more potent NO donor in the process of S-nitrosylation [5]. Another enzyme, S-nitrosoglutathione reductase (GSNOR), releases NO from GSNO and functions as a scavenger system for nitrosothiols in the biological system [6]. How these enzymes coordinate to orchestra the signaling of $\mathrm{NO}$ through S-nitrosylation is still not clear, but it is known that dysfunction of these enzymes affects some important physiological function [7-9].

\section{How S-Nitrosylated Proteins Are Identified and Detected}

Because of the labile nature of the modification, detection of S-nitrosylation in proteins remains to be a difficult task. Nitrosothiols can be detected by chemiluminescence, mass spectrometry, antibodies that recognize nitrosothiols, colorimetric or fluorometric method, and the biotin switch assay [10]. Usually, a combination of these methods is used to confirm a protein that is being S-nitrosylated [10]. Two studies have reported highthroughput proteomic approaches to identify proteins that are S-nitrosylated based on the biotin-switch assay $[11,12]$. Hao et al. [12] described their SNO-Site identification (SNOSID) approach for screening proteins that can be S-nitrosylated in brain tissue with the use of a combination of the biotin-switch assay and the liquid chromatography tandem mass spectrometry (LC-MS) analysis. Their approach involved treating the rat cerebellum homogenate with GSNO and then using the biotin switch assay to label proteins that were S-nitrosylated with biotin. This approach identified 6 endogenously Snitrosylated proteins and 58 proteins that were modified after treatment with GSNO [12]. In a similar study, 18 Snitrosylated proteins were identified in human aortic smooth muscle cells after exposure to S-nitrosocysteine or propylamine propylamine NONoate [11]. By comparing the two studies, only two proteins (microtubule-associated protein and 14-3-3) were identified in both reports $[11,12]$. These findings suggest that an approach similar to SNOSID is not a very robust method in identifying S-nitrosylated proteins from tissues. Another interesting observation from these two reports is that the Snitrosylated cysteine residues are mostly not flanked by the acid-base amino acid motif on the primary protein structures [11,12], which suggests that the 3 -dimensional acid-base motif might be more important in the process of S-nitrosylation.

\section{Neuronal Processes That Are Modulated by S-Nitrosylation}

\section{Gene Transcription}

Redox signaling is known to affect gene transcription, and NO is emerging as an important molecule that regulates gene expression in relation to redox environment. At least four well-known transcription factors are known to be modulated by NO through S-nitrosylation. NO has been shown to affect the activity of estrogen receptor, nuclear factor-kappa B (NF- $\mathrm{B}$ ), hypoxia inducible factor (HIF) and cAMP response element binding (CREB) through S-nitrosylation [13-17]. In estrogen receptor and HIF, NO directly S-nitrosylates these transcriptional factors and modulates their ability to activate gene transcription $[13,16]$. For NF- $\kappa B$ and CREB, NO mainly affects their transcriptional activities indi- 
rectly $[14,15,17]$. In the basal state, NF- $\mathrm{KB}$ is bound to inhibitory $\kappa \mathrm{B}$ (ІкВ) and is located at the cytoplasm. When the NF- $\kappa$ B pathway is activated, ІкB kinase (IKK) phosphorylates IкB and promotes IкB degradation [14,

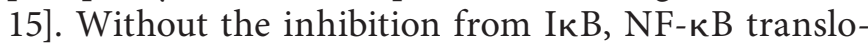
cates to the nucleus and initiates gene transcription [14, 15]. NO inhibits NF- $\kappa \mathrm{B}$ activation indirectly by S-nitrosylation of IKK and prevents the phosphorylation of IкB. This prevents the degradation of ІкB and inhibits the activation of NF- $\kappa B$ pathway $[14,15]$. CREB is an important transcriptional activator in neurotrophin signaling such as brain-derived neurotrophic factor (BDNF). A study suggests that the BDNF-induced activation of CREB is dependent on S-nitrosylation of components in the CREB DNA-binding complex [17]. However, which components are being $S$-nitrosylated during the BDNF-induced CREB transcriptional activation is not known [17].

\section{Synaptic Transmission}

NO is the first gaseous molecule that is considered as a neurotransmitter in the nervous system. The importance of NO in the synaptic transmission is best demonstrated by its effect on $\mathrm{N}$-methyl $\mathrm{D}$-aspartate receptor (NMDAR). S-nitrosylation of cysteine 399 of the NR2A subunit in the NMDAR inhibits its activity $[18,19]$. This negative feed back mechanism is facilitated by the proximate location of nNOS which is linked to the NMDAR via the PDZ domain. Since nNOS is activated by $\mathrm{Ca}^{2+}$, influx of $\mathrm{Ca}^{2+}$ during the synaptic activation of NMDAR will increase the production of NO by $\mathrm{nNOS}$. NO can modulate synaptic transmission at several levels. The NMDAR downstream signaling molecules such as p21Ras and Dexras are activated by S-nitrosylation [20-22]. In addition, S-nitrosylation of $\mathrm{N}$-ethylmaleimide sensitive factor (NSF) promotes the surface expression of $\alpha$-amino-3-hydroxy-5-methylisoxazole-4-propionic acid receptor (AMPAR) [23]. Though it is clear that the proper function of NMDAR transmission is indispensable with the NO, it remains to be determined how exactly $\mathrm{NO}$ can modulate the NMDAR synaptic transmission. Apart from modulating the NMDAR, NO also affects the transmission of G-protein-coupled receptor (GPCR) through $\mathrm{S}$-nitrosylation. A recent study has shown that S-nitrosylation of GPCR kinase (GRK) attenuates GPCR agonist induced desensitization and internalization of $\beta$-adrenergic receptor [8]. Further studies are needed to see if NO can S-nitrosylate other GRK and can affect the signal transduction of other GPCRs.

Say NO to Neurodegeneration

\section{Modulation of Physiological Function}

NO's role as a signaling molecule was first demonstrated in the cardiovascular system as an EDRF. More recent studies suggest that NO functions at different levels to regulate the respiratory and cardiovascular systems in response to metabolic demands [24, 25]. In the vascular system, $S$-nitrosylation of $\beta$-globin Cys-93 in oxyhemoglobin has been reported as a major reservoir of nitrosothiol $[24,25]$. Further studies proposed that in tissues with high metabolic demand, the release of $\mathrm{O}_{2}$ from hemoglobin will simultaneously trigger the release of NO which induces local vasodilatation to increase blood supply in these active tissues $[24,25]$. The importance of Snitrosylation in the cardiovascular system signaling is further supported by the finding that nitrosothiols released from deoxygenated blood can induce hyperventilatory response via brain stem during hypoxic condition [26].

\section{Nitric Oxide, S-Nitrosylation and Neurodegenerative Disorders}

NO has long been regarded as a contributor in the process of neurodegeneration. Early studies suggested that nitrosative stress induced by inflammatory response is an important factor for the degeneration of neurons. This is evident by the fact that increased nitration of protein aggregates are prominent in various neurodegenerative disorders such as amyotrophic lateral sclerosis (ALS), synucleinopathies, and tauopathies [27, 28]. The increased nitration of proteins can be initiated by increased production of NO during the process of neuroinflammation, and generation of free radicals by dysfunctional mitochondria which are commonly observed in various neurodegenerative disorders. The combination of free radicals such as superoxide anion and NO will result in the formation of highly reactive peroxynitrite. Peroxynitrite can then nitrate the tyrosine residues to 3-nitrotyrosine on proteins, induce lipid peroxidation, and cause DNA damage [29]. However, some studies now suggest that $\mathrm{NO}$ can contribute to the pathogenic process of neurodegeneration through S-nitrosylation of different critical proteins that are important for the survival of neurons.

Excessive nitrosative stress has long been linked to pathogenesis of amyotrophic lateral sclerosis (ALS), Alzheimer's disease (AD) and Parkinson's disease (PD). The strongest evidence for the linkage of nitrosative stress and neurodegeneration is in the presence of ni-

Neurosignals 2006-07;15:307-313 
trated protein aggregates in brain tissues of patients afflicted with these neurodegenerative disorders [27, 28]. This observation also suggests that an imbalance of Snitrosylation of proteins due to increased nitrosative stress can contribute to the pathogenesis of various neurodegenerative diseases. This notion is supported by a recent report that depletion of S-nitrosothiols by mutated superoxide dismutase 1 (SOD1) contributes to the pathogenesis of ALS [30]. ALS is a motor neuron degenerative disease characterized by adult onset and degeneration of motor neurons in the spinal cord, brain stem and cortex [31]. The disorder is mostly sporadic, but mutations in SOD1 have been linked to rare familial forms of ALS [31]. Since the discovery that SOD1 mutations cause ALS, animal model of ALS has been set up by overexpression of mutant SOD1 in mice [31]. This animal model recapitulates some fundamental features of ALS in patients such as selective degeneration of motor neurons in the spinal cord, and has proven to be a valuable tool in understanding the pathogenic mechanism of ALS. The linkage of S-nitrosylation and the development of ALS was found in a recent study that selective depletion of nitrosothiols are prominent in the spinal cords of the SOD1 mutant over-expression animal model of ALS [30]. The mechanism of how the depletion of nitrosothiols can contribute to degeneration of motor neurons in ALS is not exactly known, but more detailed study suggests that it is related to the decrease levels of S-nitrosylated GAPDH [30]. Since S-nitrosylation of GAPDH is known to regulate its translocation to the nucleus and the process is critical for cell survival, it is hypothesized that decreased S-nitrosylation of GAPDH can contribute to the demise of motor neurons in ALS [30]. The important role of nitrosative stress in AD and PD is clearly demonstrated by the prominent deposition of nitrated protein aggregates in brain tissues of affected patients $[27,32]$. The molecular mechanisms of how nitrosative stress contributes to $\mathrm{AD}$ and $\mathrm{PD}$ are not completely clear, but it is generally believe that nitration of protein can induce the formation of protein aggregates, which can ultimately cause the degeneration of neurons. Some recent findings in PD might provide the molecular mechanism of how nitrosative stress can contribute to the process of neurodegeneration.

\section{Nitrosative Stress and PD}

$\mathrm{PD}$ is a common degenerative disorder which is marked by movement impairments due to a progressive loss of tyrosine hydroxylase-positive dopaminergic neurons in the brain stem. This characteristic neuronal de- generation is accompanied by the presence of intracellular protein aggregates designated as Lewy bodies (LB) which are enriched with ubiquitin and $\alpha$-synuclein. The cause of PD is not clear, but from pathological studies, it is proposed that oxidative damage and protein aggregation is central to the pathogenesis of PD. Most PD cases are sporadic, but a small percentage of them are familiallinked. From genetic linkage studies, mutations in $\alpha$ synuclein, LRRK2 and UCH-L1 cause the autosomaldominant form of PD while mutations in PINK1, DJ-1 and parkin cause the autosomal-recessive form of $\mathrm{PD}$ [33]. Genetic and biochemical studies of these genes and their gene products have yielded new insights on how malfunctions of various pathways induce degeneration of dopaminergic neurons in PD. In agreement with the established hypothesis, genes linked to familial PD are related to mitochondria function (PINK1), handling of misfolded proteins (parkin and DJ-1) or itself is a protein that is prompt to misfolding ( $\alpha$-synuclein). If nitrosative stress is crucial in the development of PD, familial PD genes or pathways that are linked to these gene products should be sensitive to NO. Studies suggested that this is actually the case. The first evidence comes from the study that $\alpha$-synuclein, which is the major component of LB, is specifically nitrated in LB [32]. On the other hand, at least two PD familial-linked gene products have been shown to be S-nitrosylated by NO. For instance, S-nitrosylation of Cys46 in DJ-1 has been shown to affect its natural dimerization tendency, but the physiological significance of this is not clear [34]. Another PD-linked gene product that can be S-nitrosylated is parkin $[35,36]$. Mutations of parkin cause autosomal-recessive early onset parkinsonism, and biochemical studies have shown that parkin functions as an E3 ligase in the ubiquitin proteasomal system (UPS) [37]. Various studies have shown that parkin can protect neurons from different insults [38], and deletion of parkin in mouse has shown to affect the normal survival of monoaminergic neurons [39]. Parkin is a RING finger domain type E3 ligase, and one of the characteristics of this RING finger domain is the existence of considerable number of highly conserved cysteine residues within the domain. We initially suspected that these cysteine residues can be S-nitrosylated by $\mathrm{NO}$, and this modification will affect the normal function of parkin. To test this hypothesis, we performed biotin-switch and fluorometric assays [10] that can detect $\mathrm{S}$-nitrosylation under in vitro and in vivo conditions to determine if parkin can be modified by NO [35]. In agreement with our hypothesis, we and another group independently showed that parkin is modified by NO 
through S-nitrosylation under different conditions [35, 36]. S-nitrosylation of parkin impairs its E3 ligase activity and compromises its protective function. The selective dopaminergic neurotoxin 1-methyl-4-phenyl1,2,3,6-tetrahydropyridine (MPTP) is known to mediate its toxicity through the production of oxidative free radicals such as peroxynitrite [40]. Our study also confirmed that S-nitrosylation of parkin is relevant to the pathogenesis of PD as increased parkin S-nitrosylation is prominent in mouse MPTP model of PD [35]. In post-mortem brain tissues from PD patients, increased levels of both nitrosothiols and S-nitrosylated parkin were found [35]. Taken together, these findings suggested that inhibition of parkin's function by S-nitrosylation can contribute to the pathogenesis in the more common form of sporadic PD $[35,36]$.

The hypothesis that nitrosative stress through S-nitrosylation is a major contributor in the development of $\mathrm{PD}$ is supported by several recent studies. Glyceraldehyde 3-phosphate dehydrogenase (GAPDH) is a well-known enzyme that functions in the glycolysis pathway. However, a previous study showed that nuclear translocation of GAPDH is associated with a number of cell death stimulis. Interestingly in a recent study, it was shown that $\mathrm{S}$ nitrosylation of GAPDH induces its nuclear translocation through the binding of an E3 ubiquitin ligase Siah1, and this translocation was found to initiate apoptosis in the cell [41]. In the mouse MPTP model of PD, increased S-nitrosylation of GAPDH is observed in the brain of MPTP-treated animals [42]. This increase in S-nitrosylation of GAPDH can be reversed by deprenyl, which is known to provide neuroprotection against MPTP induced toxicity [42]. These studies suggest that S-nitrosylation of GAPDH is directly linked to the pathogenesis of $\mathrm{PD}$ [42].

Another recent report that supports the role of nitrosative stress in the process of neurodegeneration is the inhibition of protein-disulphide isomerase (PDI) by NO through S-nitrosylation [43]. Misfolded proteins have long been suspected to aggravate the process of neurodegeneration and it has been proposed that nitration of proteins can cause protein misfolding which can consequently damage neurons [27]. This hypothesis is supported by studies showing that overexpression of heat shock protein 70 (HSP70), which prevent protein misfolding, can protect neurodegeneration in different animal models. Whether nitrosative stress can affect the function of HSP70 related protein is not clear, but a recent study found that a protein that handles protein misfolding (PDI) can be S-nitrosylated and this modifica-

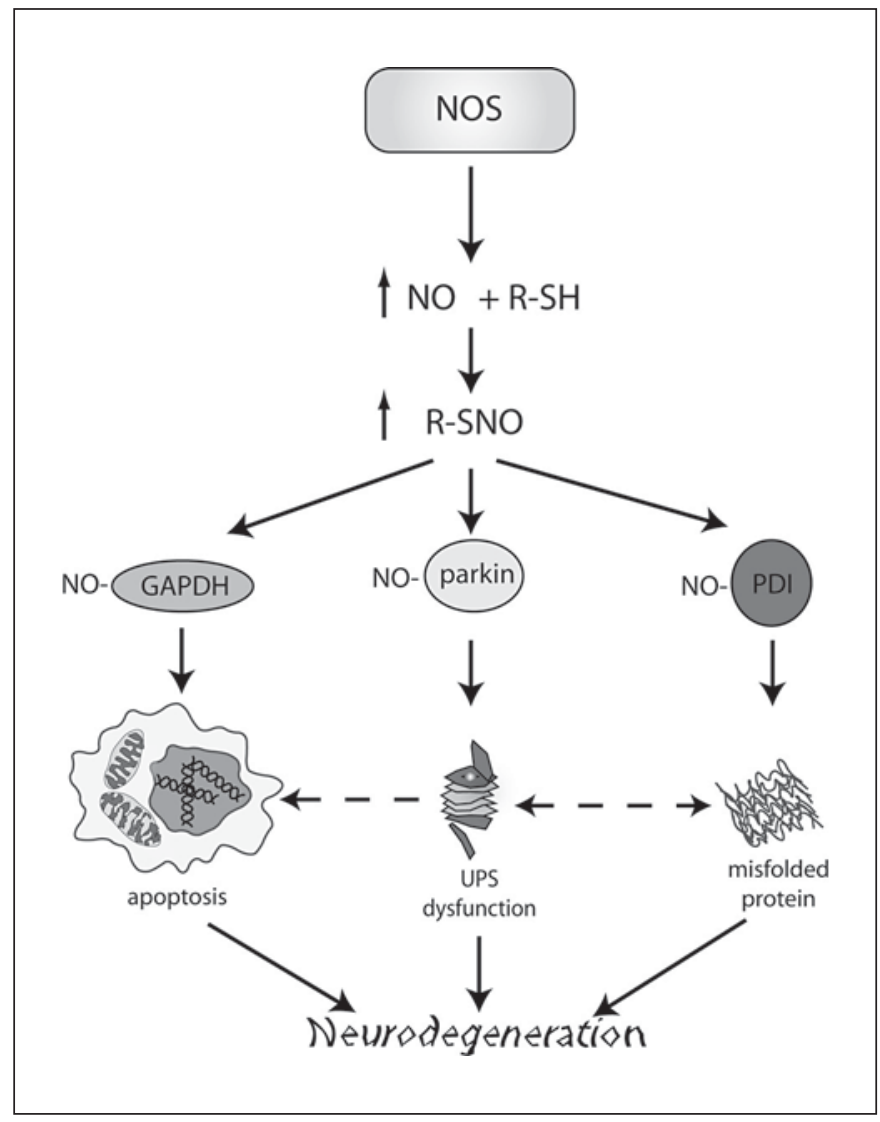

Fig. 1. Schematic diagram illustrating how nitrosative stress can contribute to neurodegeneration through S-nitrosylation of different proteins in the cell. Increased nitrosative stress due to upregulation of iNOS or nNOS activity can increase the levels of protein S-nitrosylation. S-nitrosylation of parkin and PDI inhibit their neuroprotective activities against protein misfolding and protein aggregation. Misfolded or aggregated proteins can impair the normal function of UPS and further exacerbate the process of neurodegeneration. Increased S-nitrosylation of GAPDH can promote apoptosis in neurons that have been made vulnerable because of the accumulation of misfolded or aggregated proteins.

tion is related to the pathogenesis of $\mathrm{PD}$ and $\mathrm{AD}$ [43]. PDI is an enzyme that assists the maturation and transport of unfolded proteins [43]. PDI prevents protein misfolding by assisting the proper formation of disulphide bonds in the process of protein folding [44]. The finding that S-nitrosylation of PDI can compromise its function provides another direct link between nitrosative stress and misfolded protein stress in the process of neurodegeneration. Furthermore, increased levels of PDI S-nitrosylation are observed in both $\mathrm{PD}$ and $\mathrm{AD}$ patients [43]. Taken together, these reports suggest that nitrosative stress 
through S-nitrosylation is crucial in the process of neurodegeneration (fig. 1) and further research is needed in this area.

\section{Concluding Remarks}

Increasing evidence suggests that $\mathrm{NO}$ is an important contributor to neurodegeneration. In-depth understanding of how imbalance of NO metabolism can contribute to neuronal cell death will be a crucial task in the future in order to formulate the possible neuroprotective strategies in the treatment of various neurodegenerative disorders.

\section{Acknowledgements}

KKKC is supported by grants from the Research Grants Council of Hong Kong (HKUST6435/06M, HIA05/06.SC04).

\section{References}

1 Reynolds MF, Burstyn JN: Mechanism of activation of soluble guanylyl cyclase by NO; in Ignarro L (ed): Nitric Oxide Biology and Pathobiology. San Diego, Academic Press, 2000, pp 57-82.

$\checkmark 2$ Stamler JS, Lamas S, Fang FC: Nitrosylation: the prototypic redox-based signaling mechanism. Cell 2001;106:675-683.

-3 Stamler JS, Toone EJ, Lipton SA, Sucher NJ: (S)NO signals: translocation, regulation, and a consensus motif. Neuron 1997;18:691696.

4 Knipp M, Braun O, Gehrig PM, Sack R, Vasak M: Zn(II)-free dimethylargininase-1 (DDAH-1) is inhibited upon specific Cys-Snitrosylation. J Biol Chem 2003;278:34103416.

5 Gaston B: Nitric oxide and thiol groups. Biochim Biophys Acta 1999;1411:323-333.

6 Liu L, Hausladen A, Zeng M, Que L, Heitman J, Stamler JS: A metabolic enzyme for S-nitrosothiol conserved from bacteria to humans. Nature 2001;410:490-494.

$\checkmark 7$ Liu L, Yan Y, Zeng M, Zhang J, Hanes MA, Ahearn G, McMahon TJ, Dickfeld T, Marshall HE, Que LG, Stamler JS: Essential roles of S-nitrosothiols in vascular homeostasis and endotoxic shock. Cell 2004;116:617628.

8 Whalen EJ, Foster MW, Matsumoto A, Ozawa K, Violin JD, Que LG, Nelson CD, Benhar M, Keys JR, Rockman HA, Koch WJ, Daaka Y, Lefkowitz RJ, Stamler JS: Regulation of beta-adrenergic receptor signaling by S-nitrosylation of G-protein-coupled receptor kinase 2. Cell 2007;129:511-522.

$\checkmark 9$ Lieberman MW, Wiseman AL, Shi ZZ, Carter BZ, Barrios R, Ou CN, Chevez-Barrios P, Wang Y, Habib GM, Goodman JC, Huang SL, Lebovitz RM, Matzuk MM: Growth retardation and cysteine deficiency in gammaglutamyl transpeptidase-deficient mice. Proc Natl Acad Sci USA 1996;93:79237926.
10 Chung KK, Dawson VL, Dawson TM: S-nitrosylation in Parkinson's disease and related neurodegenerative disorders. Methods Enzymol 2005;396:139-150.

11 Greco TM, Hodara R, Parastatidis I, Heijnen HF, Dennehy MK, Liebler DC, Ischiropoulos $\mathrm{H}$ : Identification of S-nitrosylation motifs by site-specific mapping of the S-nitrosocysteine proteome in human vascular smooth muscle cells. Proc Natl Acad Sci USA 2006; 45:12029-12038.

12 Hao G, Derakhshan B, Shi L, Campagne F, Gross SS: SNOSID, a proteomic method for identification of cysteine S-nitrosylation sites in complex protein mixtures. Proc Natl Acad Sci USA 2006;103:1012-1017.

13 Garban HJ, Marquez-Garban DC, Pietras RJ, Ignarro LJ: Rapid nitric oxide-mediated S-nitrosylation of estrogen receptor: regulation of estrogen-dependent gene transcription. Proc Natl Acad Sci USA 2005;102: 2632-2636.

14 Marshall HE, Hess DT, Stamler JS: S-nitrosylation: physiological regulation of NFkappaB. Proc Natl Acad Sci USA 2004;101: 8841-8842.

15 Reynaert NL, Ckless K, Korn SH, Vos N, Guala AS, Wouters EF, van der Vliet A, Janssen-Heininger YM: Nitric oxide represses inhibitory kappaB kinase through S-nitrosylation. Proc Natl Acad Sci USA 2004;101: 8945-8950.

16 Li F, Sonveaux P, Rabbani ZN, Liu S, Yan B, Huang Q, Vujaskovic Z, Dewhirst MW, Li CY: Regulation of HIF-1alpha stability through S-nitrosylation. Mol Cell 2007;26: 63-74.

17 Riccio A, Alvania RS, Lonze BE, Ramanan N, Kim T, Huang Y, Dawson TM, Snyder SH, Ginty DD: A nitric oxide signaling pathway controls CREB-mediated gene expression in neurons. Mol Cell 2006;21:283-294.

18 Choi YB, Tenneti L, Le DA, Ortiz J, Bai G, Chen HS, Lipton SA: Molecular basis of NMDA receptor-coupled ion channel modulation by S-nitrosylation. Nat Neurosci 2000;3:15-21.
19 Lipton SA, Choi YB, Takahashi H, Zhang D, Li W, Godzik A, Bankston LA: Cysteine regulation of protein function - as exemplified by NMDA-receptor modulation. Trends Neurosci 2002;25:474-480.

20 Fang M, Jaffrey SR, Sawa A, Ye K, Luo X, Snyder SH: Dexras1: a G protein specifically coupled to neuronal nitric oxide synthase via CAPON. Neuron 2000;28:183-193.

21 Jaffrey SR, Erdjument-Bromage H, Ferris CD, Tempst P, Snyder SH: Protein S-nitrosylation: a physiological signal for neuronal nitric oxide. Nat Cell Biol 2001;3:193-197.

22 Yun HY, Gonzalez-Zulueta M, Dawson VL, Dawson TM: Nitric oxide mediates N-methyl-D-aspartate receptor-induced activation of p21ras. Proc Natl Acad Sci USA 1998;95: 5773-5778.

23 Huang Y, Man HY, Sekine-Aizawa Y, Han Y, Juluri K, Luo H, Cheah J, Lowenstein C, Huganir RL, Snyder SH: S-nitrosylation of $\mathrm{N}$-ethylmaleimide sensitive factor mediates surface expression of AMPA receptors. Neuron 2005; 46:533-540.

24 McMahon TJ, Moon RE, Luschinger BP, Carraway MS, Stone AE, Stolp BW, Gow AJ, Pawloski JR, Watke P, Singel DJ, Piantadosi CA, Stamler JS: Nitric oxide in the human respiratory cycle. Nat Med 2002;8:711-717.

25 Pawloski JR, Hess DT, Stamler JS: Export by red blood cells of nitric oxide bioactivity. $\mathrm{Na}-$ ture 2001;409:622-626.

26 Lipton AJ, Johnson MA, Macdonald T, Lieberman MW, Gozal D, Gaston B: S-nitrosothiols signal the ventilatory response to hypoxia. Nature 2001;413:171-174.

-27 Duda JE, Giasson BI, Chen Q, Gur TL, Hurtig HI, Stern MB, Gollomp SM, Ischiropoulos H, Lee VM, Trojanowski JQ: Widespread nitration of pathological inclusions in neurodegenerative synucleinopathies. Am J Pathol 2000;157:1439-1445. 
28 Horiguchi T, Uryu K, Giasson BI, Ischiropoulos $\mathrm{H}$, LightFoot $\mathrm{R}$, Bellmann $\mathrm{C}$, Richter-Landsberg C, Lee VM, Trojanowski JQ: Nitration of tau protein is linked to neurodegeneration in tauopathies. Am J Pathol 2003; 163:1021-1031.

-29 Ischiropoulos H, Beckman JS: Oxidative stress and nitration in neurodegeneration: cause, effect, or association? J Clin Invest 2003; 111:163-169.

-30 Schonhoff CM, Matsuoka M, Tummala H, Johnson MA, Estevez AG, Wu R, Kamaid A, Ricart KC, Hashimoto Y, Gaston B, Macdonald TL, Xu Z, Mannick JB: S-nitrosothiol depletion in amyotrophic lateral sclerosis. Proc Natl Acad Sci USA 2006;103:2404-2409.

- 31 Boillee S, Vande Velde C, Cleveland DW: ALS: a disease of motor neurons and their nonneuronal neighbors. Neuron 2006;52: 39-59.

-32 Giasson BI, Duda JE, Murray IV, Chen Q, Souza JM, Hurtig HI, Ischiropoulos H, Trojanowski JQ, Lee VM: Oxidative damage linked to neurodegeneration by selective alpha-synuclein nitration in synucleinopathy lesions. Science 2000;290:985-989.
33 Shen J: Protein kinases linked to the pathogenesis of Parkinson's disease. Neuron 2004; 44:575-577.

34 Ito G, Ariga H, Nakagawa Y, Iwatsubo T: Roles of distinct cysteine residues in S-nitrosylation and dimerization of DJ-1. Biochem Biophys Res Commun 2006;339:667-672.

35 Chung KK, Thomas B, Li X, Pletnikova O, Troncoso JC, Marsh L, Dawson VL, Dawson TM: S-nitrosylation of parkin regulates ubiquitination and compromises parkin's protective function. Science 2004;304:13281331.

36 Yao D, Gu Z, Nakamura T, Shi ZQ, Ma Y, Gaston B, Palmer LA, Rockenstein EM, Zhang Z, Masliah E, Uehara T, Lipton SA: Nitrosative stress linked to sporadic Parkinson's disease: S-nitrosylation of parkin regulates its E3 ubiquitin ligase activity. Proc Natl Acad Sci USA 2004; 101:10810-10814.

37 Chung KK, Dawson VL, Dawson TM: New insights into Parkinson's disease. J Neurol 2003;250(suppl 3):III15-24.

38 Feany MB, Pallanck LJ: Parkin: a multipurpose neuroprotective agent? Neuron 2003; 38:13-16.

39 Von Coelln R, Thomas B, Savitt JM, Lim KL, Sasaki M, Hess EJ, Dawson VL, Dawson TM: Loss of locus coeruleus neurons and reduced startle in parkin null mice. Proc Natl Acad Sci USA 2004;101:10744-10749.
40 Zhang Y, Dawson VL, Dawson TM: Oxidative stress and genetics in the pathogenesis of Parkinson's disease. Neurobiol Dis 2000;7: 240-250.

41 Hara MR, Agrawal N, Kim SF, Cascio MB, Fujimuro M, Ozeki Y, Takahashi M, Cheah JH, Tankou SK, Hester LD, Ferris CD, Hayward SD, Snyder SH, Sawa A: S-nitrosylated GAPDH initiates apoptotic cell death by nuclear translocation following Siah1 binding. Nat Cell Biol 2005; 7:665-674.

42 Hara MR, Thomas B, Cascio MB, Bae BI, Hester LD, Dawson VL, Dawson TM, Sawa A, Snyder SH: Neuroprotection by pharmacologic blockade of the GAPDH death cascade. Proc Natl Acad Sci USA 2006;103: 3887-3889.

43 Uehara T, Nakamura T, Yao D, Shi ZQ, Gu Z, Ma Y, Masliah E, Nomura Y, Lipton SA: Snitrosylated protein-disulphide isomerase links protein misfolding to neurodegeneration. Nature 2006;441:513-517.

44 Ellgaard L, Ruddock LW: The human protein disulphide isomerase family: substrate interactions and functional properties. EMBO Rep 2005;6:28-32. 